\title{
Self processes in interdependent relationships
}

\section{Partner affirmation and the Michelangelo phenomenon}

\author{
Caryl E. Rusbult ${ }^{1}$, Madoka Kumashiro ${ }^{1}$, Shevaun L. Stocker ${ }^{2}$, \\ Jeffrey L. Kirchner ${ }^{2}$, Eli J. Finkel ${ }^{3}$ and Michael K. Coolsen ${ }^{4}$ \\ ${ }^{1}$ Free University at Amsterdam / ${ }^{2}$ University of North Carolina at Chapel \\ Hill / ${ }^{3}$ Northwestern University / ${ }^{4}$ Shippensburg University
}

This essay reviews theory and research regarding the "Michelangelo phenomenon," which describes the manner in which close partners shape one another's dispositions, values, and behavioral tendencies. Individuals are more likely to exhibit movement toward their ideal selves to the degree that their partners exhibit affirming perception and behavior, exhibiting confidence in the self's capacity and enacting behaviors that elicit key features of the self's ideal. In turn, movement towards the ideal self yields enhanced personal well-being and couple well-being. We review empirical evidence regarding this phenomenon and discuss self and partner variables that contribute to the process.

Keywords: self processes, ideal self, partner affirmation, close relationships, interdependence, behavioral confirmation, personal well-being

The research reviewed in this essay examines an interaction process that bridges the gap between intrapersonal psychology and interpersonal psychology. In brief, our research explores the ways in which interpersonal experience shapes the self, including personal dispositions, values, and behavioral tendencies. ${ }^{1}$ Our work rests on the assumption that the self does not spring full-blown from a vacuum - rather, the self is fashioned at least in part by interpersonal experience. The interpersonal agents who exert the most powerful effects on the self are those with whom we are most strongly interdependent - friends, family, 
and romantic partners. Such influence can be very positive or very negative: Some partners bring out the best in one another, whereas others either fail to do so or bring out the worst in one another.

This essay presents theory and research regarding an interaction process termed the Michelangelo phenomenon. We begin by addressing three theoretical traditions that form the basis for our work - the behavioral confirmation, interdependence, and self-discrepancy traditions. Then we introduce the Michelangelo phenomenon and its consequences, introducing the concepts of partner affirmation and movement toward the ideal self. After outlining empirical findings relevant to key predictions, we distinguish this phenomenon from related interaction processes, including partner affirmation, partner verification, self-other merger, and the Pygmalion phenomenon. We close with a review of specific self and partner processes in the Michelangelo phenomenon.

\section{Theoretical background}

\section{Behavioral confirmation processes}

Our theoretical analysis begins with the concept of behavioral confirmation, defined as the means by which an interaction partner's expectations about the self become reality by eliciting behaviors from the self that confirm the partner's expectations (Darley \& Fazio, 1980; Snyder, Tanke, \& Berscheid, 1977; also see Klein, this volume). How does this process unfold? Interaction partners develop beliefs about the self's strengths and limitations, preferences and disinclinations. During interaction, partners tend to act in accord with their beliefs about the self. In so doing, partners create opportunities for the self to display some behaviors, constrain interaction in such a manner as to inhibit the display of other behaviors, and thereby elicit a subset of the self's full repertoire of possible behaviors (e.g., Harris \& Rosenthal, 1985).

\section{Self-discrepancy processes}

Is behavioral confirmation likely to be a good thing or a bad thing? And importantly, how should we conceptualize "good thing" versus "bad thing?" Is behavioral confirmation "good" when it is enhancing, or elicits normatively desirable behaviors from the self? Is it "good" when it is verifying, or elicits behaviors that are compatible with the individual's self-conception? Our answer begins as a metaphor, and rests on the manner in which sculpting was envisioned by 
its greatest practitioner: "Michelangelo conceived his figures as lying hidden in the block of marble... The task he set himself as a sculptor was merely to extract the ideal form... to remove the stone that covered [the ideal]" (Gombrich, 1995, p. 313). As such, the creative process and the artist's tools are aspects of salvation, in that by chipping away at the stone, the figure slumbering in the block is allowed to emerge. In Michelangelo's vision, the slumbering figure was something heroic, vibrant, and divine - the "ideal form."

Like blocks of stone, humans, too, possess ideal forms. The human equivalent of Michelangelo's slumbering form is a possible self to which the individual aspires (Higgins, 1987, 1996; Markus \& Nurius, 1986). In particular, humans can be said to possess an ideal self, defined as the constellation of dispositions, motives, and behavioral tendencies an individual ideally wishes to acquire. People experience distress when they perceive discrepancies between the ideal self and the actual self, defined as the dispositions, motives, and behavioral tendencies an individual believes he or she actually possesses. The distress associated with actual-self/ideal-self discrepancies is motivating - people seek to bring the actual self into alignment with the ideal self (e.g., Moretti \& Higgins, 1990).

\section{Interdependence processes}

Among the many interpersonal forces that shape the self, few sculptors are likely to exert effects as powerful as those of our close partners. How so? To begin with, extended interdependence involves adaptation - over time in a relationship, interacting individuals adjust to one another by selectively developing some aspects of the self and eliminating others (Kelley \& Thibaut, 1978; Rusbult \& Van Lange, 2003; also see Vallacher, this volume). Moreover, strong interdependence provides particularly good opportunities for mutual influence and adaptation, in that strong interdependence entails frequent and powerful influence across diverse types of activity. Over the course of repeated interaction in the context of strong interdependence, each person's interaction-specific adaptations eventually become embodied in stable dispositions, values, and behavioral tendencies: Each person's self is sculpted by the partner; each person's dispositions, values, and behavioral tendencies come to reflect the particular conditions of interdependence experienced with the partner. 


\section{The Michelangelo phenomenon and its consequences}

\section{Partner affirmation versus disaffirmation}

The concept of partner affirmation describes the manner in which a partner sculpts the self, or the degree to which the partner is an ally (vs. foe) in the self's goal pursuits. Partner perceptual affirmation describes the degree to which a partner believes that the self can acquire ideal-congruent qualities: Does Mary "see the best in what John might be?" As illustrated in Figure 1, we suggest that partner perceptual affirmation promotes partner behavioral affirmation, which describes the degree to which a partner behaves toward the self in such a manner as to elicit ideal-congruent qualities: Does Mary "draw out the best in John?" In turn, behavioral affirmation yields self movement toward the ideal self: John becomes a reflection of that which he ideally wishes to be. This threestep process is the Michelangelo phenomenon (Drigotas, Rusbult, Wieselquist, \& Whitton, 1999).

Thus, the Michelangelo metaphor describes a beneficent unfolding of the confirmation process. For instance, imagine that John wants to become a warmer and more affable person. If Mary's perceptions of John are congruent

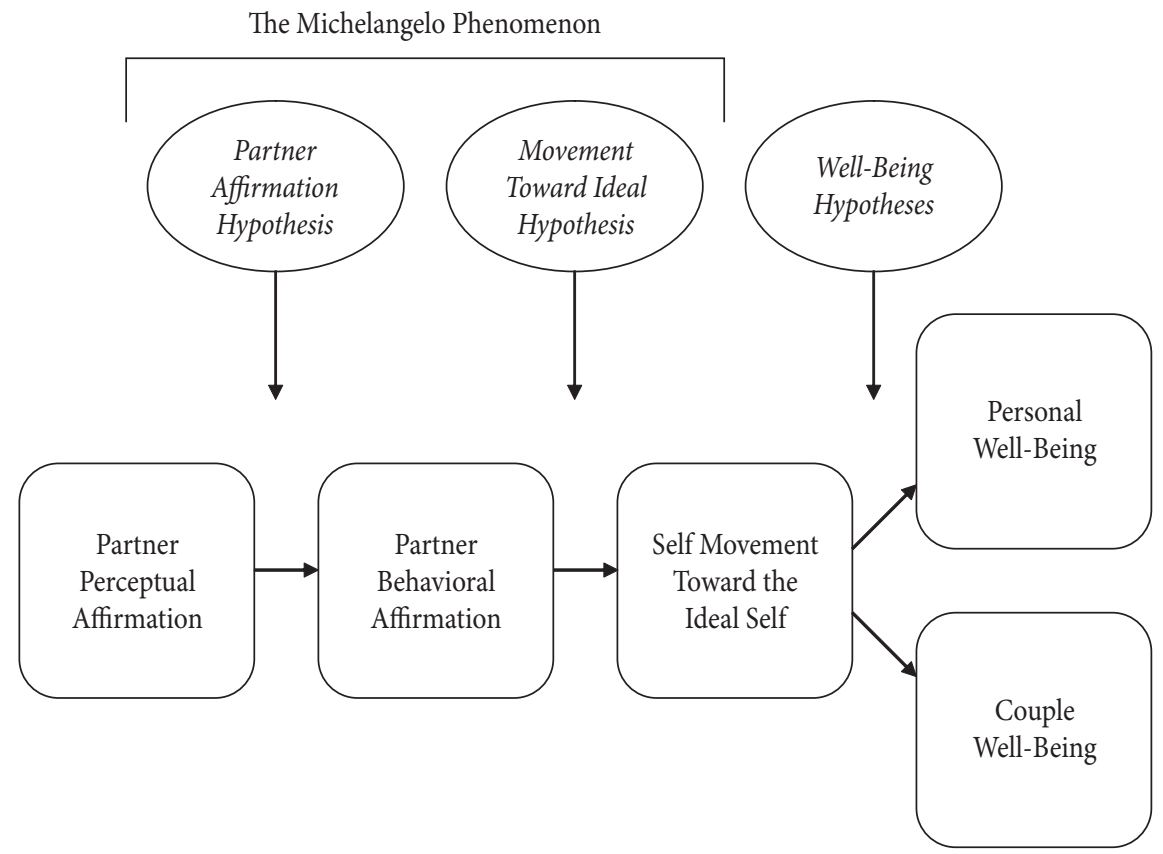

Figure 1. The Michelangelo phenomenon, personal well-being, and couple well-being. 
with his ideal self - if she thinks he has the capacity to become a warmer and more affable person - she is likely to "sculpt" toward that ideal, eliciting behaviors that are consistent with John's ideal self. For instance, at a nerveracking dinner with John's new boss, Mary may direct conversation in such a manner as to elicit a convivial story from John, putting him at ease and helping him display his best self. Over the course of frequent interactions during which Mary helps John display his best self, John will flourish, moving closer to the genuinely genial person that he wishes to become.

Of course, partner sculpting may bring out the best or the worst in the self. The concept of affirmation is a continuum, ranging from affirmation at the upper end of the continuum, through failure to affirm, to disaffirmation at the lower end of the continuum. There are two ways in which the process may go awry. First, a partner's perceptions and behavior may be antithetical to the self's ideal. In truth, Mary may believe that John is socially inept. On the basis of this belief, she may inadvertently (or deliberately) create situations in which John appears inept. John may find it difficult to behave in a friendly and forthcoming manner when Mary is present, and may become increasingly socially awkward. Eventually, John may recognize that he is not at his best around Mary, and may feel dismayed that her opinion of him is antithetical to his ideal self.

Second, a partner's perceptions and behavior may be oriented toward goals that are irrelevant to the self's ideal. For instance, Mary may "love John for the wrong reasons" - she may love him for his strength and instrumental abilities. Mary may praise John for being hardnosed, or may exert effort in support of his professional advancement. John may value Mary's admiration, and may even become a stronger and more instrumental person. However, if strength is not a central component of John's ideal self, then Mary's actions - however positive and well-intentioned - must be seen as irrelevant to that which he holds most dear. Mary will play no role in promoting John's central goals and aspirations, and eventually, John may recognize that Mary has rather thoroughly "missed the boat" about him.

\section{Personal well-being and couple well-being}

As illustrated in Figure 1, we suggest that the Michelangelo phenomenon has important consequences for both personal well-being and couple well-being. Why might this phenomenon promote personal well-being? Many social scientists have proposed such an association, arguing that growth striving is a primary human motive. For instance, Freud (1923) argued for such a motive in 
his discussion of ego ideal, Rogers (1961) and Maslow (1962) described such a motive in terms of self-actualization, and Bowlby (1969) addressed growth striving in his concept of exploration. Contemporary motivation theories, too, emphasize the importance of self-determination and personal growth (Deci \& Ryan, 2000; Emmons, 2003). To the extent that striving for personal growth is indeed a primary motive, when people move closer to their ideal selves, this motive is gratified. Thus, movement toward the ideal self should be associated with a wide range of personal benefits, including enhanced life satisfaction and superior psychological adjustment; movement away from the ideal self is likely to yield decrements in personal well-being, in the form of dejection and depression (Higgins, 1987).

Why might this phenomenon promote couple well-being? To begin with, a partner who perceptually affirms the self demonstrates empathic understanding, which in turn should enhance feelings of love ("you see me as I ideally want to be"; Ickes, Stinson, Bissonnette, \& Garcia, 1990). In addition, behavioral affirmation promotes outcome correspondence and ease of coordination, in that the behaviors of self and partner are synchronized (rather than at odds) in their orientation to the self ("we act in harmony, toward shared goals"; Rusbult \& Van Lange, 2003). And finally, assuming that movement toward the ideal self is gratifying in itself, partners who yield such gratifications are likely to be highly valued ("I'm a better person when I'm with you"; Deci \& Ryan, 2000; Emmons, 2003).

Thus, we suggest that individuals grow and relationships flourish not so much as a simple consequence of partner enhancement (Mary elicits an idealized image of John; Murray, Holmes, \& Griffin, 1996) or partner verification (Mary elicits qualities that are congruent with John's self-perception; Swann, DeLaRonde, \& Hixon, 1994) or self-other merger (Mary and John acquire one another's dispositions; Aron \& Aron, 2000). Rather, we suggest that individuals and relationships are most likely to flourish when partners effectively elicit and nurture one another's ideal selves; individuals and relationships stagnate and languish when partners block or inhibit one another's movement toward the ideal self.

\section{Empirical evidence regarding the Michelangelo phenomenon}

We have observed consistent support for model predictions using both experimental and nonexperimental methods, employing both obtrusive and unobtrusive measures, in the context of a wide range of relationships. For example, in one study we asked each participant to bring a friend to the research session; 
we obtained descriptions of participants and their partners via both self-report (from participants) and peer report (from friends; Drigotas et al., 1999). Importantly, we observed good support for predictions in analyses examining the association of participant-reported criteria with friend-reported predictors: Friends' descriptions of the participant's partner (does the partner elicit the participant's ideal self?) were predictive of participant descriptions of their own movement toward the ideal self, as well as whether, three months later, the relationship had persisted versus ended.

In other studies we asked couples to discuss each person's pursuit of an important personal goal (Rusbult et al., 2004a, 2004b). We used videotapes of these conversations to develop two types of behavioral measure: (a) participants later reviewed their conversation, providing on-line ratings of both their own and the partner's behavior; and (b) we developed a coding scheme to tap relevant variables, and trained research assistants to rate both target and agent behaviors (e.g., "partner criticized target's goal pursuits," "target expressed determination about goal pursuits"). Independent of this conversation, participants completed measures of personal well-being and couple well-being. Analyses examining both types of behavioral measure revealed that when partners were judged to display more insightful and affirming behaviors, selves exhibited greater confidence about their ideals, selves reported greater subjective well-being, and relationships scored higher in adjustment.

And finally, we have obtained experimental support for model predictions. For example, in a "getting acquainted" study, participants received information about a target person's first impressions - information about traits the target believed they possessed (Kumashiro, Wolf, Coolsen, \& Rusbult, 2004). This information centered on qualities the participant had earlier identified as part of his or her ideal self, indifferent self, or feared self. Participants were asked to predict their interaction experiences with the target. In comparison to the feared-self and indifferent-self conditions, in the ideal-self condition - where the target thought the participant possessed ideal-self attributes - participants anticipated that they would like the target more, and predicted that interaction with the target would be more pleasant.

Before moving on, two additional findings should be noted: First, mediation analyses routinely reveal support for our model of direct and indirect causal effects, demonstrating that (a) partner behavioral affirmation significantly (and fully) mediates the association of perceptual affirmation with self movement toward ideal, and (b) self movement toward ideal significantly (yet partially) mediates the association of behavioral affirmation with both personal 
well-being and couple well-being (Drigotas et al., 1999; Rusbult et al., 2004a, 2004b). (Interestingly, in several studies we have found that $[c]$ in predicting couple well-being, behavioral affirmation may be as important as [or more important than] self movement toward ideal.) Second, analyses of longitudinal data reveal that (a) earlier partner affirmation predicts change over time in movement toward the ideal self, and (b) earlier affirmation and movement toward ideal predict change over time in personal well-being and couple wellbeing (Drigotas et al., 1999; Rusbult et al., 2004a, 2004b). And importantly, such associations are evident even when we statistically control for a variety of potential confounds, including self-esteem, depression, and socially desirable response tendencies (Drigotas et al., 1999; Kumashiro, Rusbult, \& Estrada, 2004; Rusbult, 2004a, 2004b).

\section{How the Michelangelo phenomenon differs from other self-relevant interaction processes}

Of course, our model is not the only extant theory that addresses self processes in ongoing relationships. Accordingly, it is important to distinguish the Michelangelo phenomenon from related interpersonal processes - processes to which it bears some similarity, or with which it may share some common themes. In the following paragraphs we consider how partner affirmation relates to alternative self-relevant processes.

\section{Partner affirmation and partner enhancement}

How does partner affirmation differ from partner enhancement, or partner behavior that is exceptionally positive with regard to the self (i.e., idealization, positive illusion)? Many studies have revealed that partner enhancement yields good consequences, demonstrating that selves whose partners view them favorably not only are more satisfied with their relationships, but also develop increasingly positive self-images (e.g., Murray et al., 1996). Empirically, enhancement and affirmation are likely to be positively associated, in that when partners exhibit affirming behavior, their actions are also likely to be experienced as quite positive, or enhancing. To "unconfound" these variables, we must define enhancement in terms of normative desirability, or the degree to which an elicited trait is "desirable for people of your age and sex." For example, in the experiment in which participants received false feedback about a target 
person's first impressions, this information concerned the participant's ideal self, indifferent self, or feared self, and was high, medium, or low in normative desirability (Kumashiro et al., 2004b). Analyses performed on key criteria - including liking for the target and anticipated pleasantness of interaction - revealed reliable effects of affirmation, along with weak or nonsignificant effects of enhancement. Thus, in the final analysis, people prefer that their partners elicit behaviors that are positive and congruent with their ideal selves, rather than eliciting behaviors that are merely normatively desirable. ${ }^{2}$

\section{Partner affirmation and partner verification}

How does partner affirmation relate to partner verification, or behavior that elicits the actual self (or the self's beliefs about the actual self)? Many studies have revealed that people value feedback that confirms their preexisting self-conceptions. For example, positive partner regard is valued and enhances intimacy among people with high self-esteem, whereas positive partner regard is unpleasant for those with low self-esteem (Swann et al., 1994; also see Swann, this volume). How can we reconcile such findings with work regarding the benefits of partner affirmation? First, we suggest that to competently affirm the self's ideal, partners must accurately perceive the block of stone they seek to sculpt (e.g., what possibilities are inherent in the block, what flaws must be circumvented?) - that is, to affirm John, Mary must possess a reasonably accurate (implicit or explicit) understanding of his actual self. Second, we suggest that although selves may appreciate partners who accurately perceive their strengths and limitations, they also want to be loved despite their limitations, and hope that the partner will behave in such a manner as to help translate the actual self into the ideal self. We have conducted several studies to examine the simultaneous effects of affirmation and verification, and have found that (a) partner affirmation consistently accounts for unique variance in key criteria beyond partner verification, (b) partner verification frequently accounts for unique variance beyond partner affirmation, and (c) the associations among Michelangelo model variables typically are not moderated by the self's level of self-esteem (Drigotas et al., 1999; Kumashiro et al., 2004a; Rusbult et al., 2004a, 2004b). Thus, it is well and good to have a partner "let you be the real you," but it is equally important that the partner "help you become the ideal you." Moreover, there is no necessary inconsistency between eliciting another's actual self and eliciting his or her ideal self. These variables sometimes operate in concert, such that both tendencies contribute to personal growth and couple vitality. 


\section{Partner affirmation and self-other merger}

How does the Michelangelo phenomenon differ from self-other merger (Aron \& Aron, 2000)? Humans arguably are motivated by the need for self-expansion - for greater physical and social influence, cognitive complexity, and social identity. Some research suggests that close involvement provides a means of self-expansion, in that strong interdependence involves inclusion of other in the self, or incorporating a partner's attributes and resources (Aron \& Aron, 2000). However, it is unclear whether the benefits of self-other merger are attributable to the full panoply of acquired partner attributes, or whether such benefits are mainly attributable to the acquisition of desirable partner attributes. We suggest that it is not straightforward self-expansion, but ideal-self-expansion - or expansion toward the ideal self - that promotes personal well-being and couple vitality. That is, including Mary in his self should benefit John mainly when such inclusion promotes John's movement toward his ideal self; embracing Mary's less-than-ideal dispositions is unlikely to be helpful. Moreover, we suggest that beneficial self-other merger may come about in part because a partner possesses key components of the self's ideal. In two studies examining this line of reasoning, mediation analyses demonstrated that: (a) Michelangelo model variables partially to wholly mediate the associations of self-other merger with key criteria; (b) partner possession of the self's ideal partially mediates the associations of Michelangelo model variables with key criteria; and (c) partner possession of the self's ideal partially to wholly accounts for the associations of self-other merger with key criteria (Rusbult et al., 2004a, 2004b). Thus, self-other merger is particularly beneficial when it entails acquiring partner qualities that are components of one's ideal self. Moreover, when a partner possesses qualities that are important components of one's ideal, the partner is better able to affirm the self's ideal (encouraging and challenging the self) and the self is better able to use the partner as a model and inspiration for movement toward the ideal.

\section{Partner affirmation and the Pygmalion phenomenon}

How does the Michelangelo phenomenon differ from the Pygmalion phenomenon? Whereas the Michelangelo phenomenon describes a partner who sculpts toward the self's ideal, the Pygmalion phenomenon describes a partner who sculpts toward the partner's ideal. Of course, if the self's ideal and the partner's ideal are compatible, this issue becomes moot. However, in two longitudinal studies, we have found that when self ideals and partner ideals for the self are 
incompatible, a partner's inclination to "foist his or her own ideals onto the self" yields negative consequences (Rusbult et al., 2004a, 2004b). Thus, not all sculpting is beneficial. When partners sculpt one another toward their own ideals rather than the self's ideals - even when such sculpting is masterful and yields a lovely product - the consequences are maladaptive for both selves and couples.

\section{Self processes and partner processes in the Michelangelo phenomenon}

\section{Self processes: The block of stone and the slumbering figure}

Our work emphasizes internally-defined ideals - the goals the self genuinely wishes to achieve, not the goals that parents, colleagues, friends, or lovers think the self ought to achieve. In distinguishing between the ideal self and the ought self, it has been argued that: (a) pursuit of the ideal self centers on aspirations, whereas pursuit of the ought self centers on obligations; (b) movement toward the ideal self yields exhilaration, whereas movement toward the ought self yields comfort; and (c) disparities from the ideal self induce dejection, whereas disparities from the ought self induce anxiety (Higgins, 1987, 1996). As such, pursuit of the ideal self is at the core of personal growth strivings. Of course, the emergence of the ideal self is not necessarily a solitary activity - selves may embrace ideals with interpersonal origins. For instance, John's desire to acquire greater warmth may be shaped by the fact that he adored his Aunt Rosemary, an easy-going woman with a talent for putting others at ease. Or for instance, Mary may seek to become an art history expert in part because John introduced her to the world of art during their travels in Italy.

We suggest that the emergence and evolution of the ideal self may best be described as an incremental process - that is: (a) although ideals may sometimes emerge full-blown in a flash of insight, they may just as often (perhaps even typically) develop in a gradual, step-by-step manner; (b) the emergence and modification of ideals may entail systematic or automatic cognitive processes - the ideal self may comprise carefully articulated goals or vaguely conceived yearnings, it may be a salient component of the self's everyday activities or may exist largely at an unconscious level; and (c) the ideal self is not a static construct - ideals typically evolve over time. Moreover, we suggest that motivation to realize one's ideal self is relatively constant across the lifespan. Although the character of the ideal self may vary over the life course - centering on industry or professional achievement at one life stage, centering on intimacy at another stage, and centering on generativity or ego integrity at yet 
other stages (Erikson, 1950) - we assume that the desire to realize one's ideals (whatever their character) is a relatively abiding human concern.

What qualities of the self are relevant to understanding movement toward one's ideal? In ongoing work we are examining three classes of variable that are relevant to understanding the Michelangelo phenomenon - to variables resting on the self's insight, ability, and motivation. First, movement toward the ideal self should be more probable to the extent that individuals possess greater insight, or greater clarity in their actual and ideal selves. Second, movement toward the ideal self should be more probable to the extent that an individual possesses adequate ability, including goal-relevant skills, control over relevant resources, the ability to develop strategies for goal attainment, and a sense of efficacy with respect to the goal at hand. And third, movement toward the ideal self should be more probable to the extent that motivation is greater, including commitment to the goal, the inclination to delay gratification, high self-esteem and self-confidence, and strong promotion orientation.

Of course, although some ideals are pursued and attained chiefly as a result of the self's actions, selves frequently benefit from the backing of insightful, able, and motivated sculptors. In ongoing work, we are also addressing qualities of the self that elicit partner affirmation. Partner affirmation should be facilitated to the extent that an individual: (a) elicits partner insight, or clear understanding of the self's ideals (John must make his ideals "visible" to Mary, sharing his dreams and aspirations); (b) elicits partner ability, or calls forth the skills that are relevant to promoting the self's ideals (John must capably signal his needs and convey what types of assistance would be most helpful); and (c) elicits partner motivation, or genuine desire to promote the self's ideals (John must inspire Mary's commitment to his goals, and express gratitude for her efforts on his behalf).

\section{Partner processes: The sculptor and the slumbering figure}

By what mechanisms do partners "select" certain of the self's behaviors, motives, or dispositions? First, partners may engage in retroactive selection, wherein they reward (or punish) certain of the self's preferences or behaviors. For instance, when John enacts warm and friendly behaviors at a dinner party, Mary may reinforce such behavior by affectionately touching his arm. Second, partners may engage in preemptive selection, wherein they enact specific behaviors that elicit (or inhibit) certain preferences or behaviors on the part of the self. For instance, in a situation wherein John might normally feel self-conscious, 
Mary may call attention to a photograph of John's closest buddies, thereby introducing a signal that instigates a calm and caring mood. And third, partners may engage in situation selection, wherein they create situations in which certain of the self's preferences or behaviors become more probable (or less probable). For instance, at a nerve-racking dinner party, Mary may preemptively steer conversation in such a manner as to elicit John's warm and other-oriented behaviors.

Moreover, some forms of affirmation are active (steering the self toward situations in which the self will excel) whereas others are passive (providing unconditional support, a secure emotional environment); some forms are deliberate (offering information, instrumental support) whereas others are inadvertent (unconsciously serving as a model). And importantly, affirmation is not necessarily warm and gentle; sometimes affirming behavior is "tough." For instance, Mary may sometimes affirm John by crossly telling him to quit thinking about himself and instead put himself in others' shoes, imagining what would make others feel loved and valued. Also, effective affirmation is not necessarily consciously controlled (Bargh \& Chartrand, 1999): On some occasions Mary may consciously seek to promote John's warm and caring behavior; on other occasions she may unconsciously and automatically exhibit affirming perception and behavior. For instance, if Mary believes that "kindness defines good manners," she may project her ideals onto John, unconsciously behaving toward him as she, herself, would most like to be treated.

In our ongoing work, we assume that the partner attributes promoting effective affirmation can also be characterized in terms of insight, ability, and motivation. First, effective affirmation should be facilitated by partner insight, or a clear understanding of the self's actual and ideal selves; accurate knowledge should be enhanced by variables such as empathy and perspective-taking. Second, effective affirmation should be enhanced by partner ability, or possession of the skills and resources relevant to promoting the self's ideals - proposing effective strategies, delivering the precise type of assistance that is needed (instrumental and social-emotional support), directly assisting the self, and actively participating in the self's goal pursuits. And third, effective affirmation should be facilitated by partner motivation, or genuine desire to promote the self's ideal - unconditional support, genuine enthusiasm for the self's goal pursuits, willingness to sometimes sacrifice personal interests to promote the self's goals (exerting effort, enduring costs), and an inclination to regard the self's pursuits as a "team effort." 


\section{Conclusions}

Our work incorporates concepts from the behavioral confirmation, self-discrepancy, and interdependence traditions to identify processes that are central to understanding the self in its relational context. The Michelangelo phenomenon is a congenial pattern of interdependence in which close partners sculpt one another in such a manner as to bring each person closer to his or her ideal self. To date, empirical evidence suggests that key components of this phenomenon relate to one another in predicted ways. Recent findings also begin to identify the processes and mechanisms that underlie the Michelangelo phenomenon, including a variety of self and partner dispositions, motives, and behavioral tendencies. We hope that such findings may extend our understanding of the social nature of the self, highlighting one means by which adaptation to interdependence partners shapes human dispositions, values, and behavioral tendencies.

\section{Acknowledgment}

The research reviewed in this essay was supported by grants from the National Science Foundation (BCS-0132398), Fetzer Institute, and Templeton Foundation.

\section{Notes}

1. The two members of a dyad may act as both target and agent. Throughout this essay, we use "self" to describe the target, or the object of another's perception and behavior, and we use "partner" to describe the agent, or the person who directs behavior toward the target and influences the target's dispositions, values, and behavioral tendencies.

2. Of course, this issue frequently boils down to terminology, in that when researchers operationally define enhancement in terms of what the self regards as positive (e.g., as in Murray et al., 1996), enhancement is tantamount to affirmation (and, perhaps, should be described as such).

\section{References}

Aron, A., \& Aron, E. (2000). Self-expansion motivation and including other in the self. In W. Ickes \& S. Duck (Eds.), The social psychology of personal relationships (pp. 109-128). New York: Wiley. 
Bargh, J. A., \& Chartrand, T. L. (1999). The unbearable automaticity of being. American Psychologist, 54, 462-479.

Bowlby, J. (1969). Attachment and loss: Vol. 1, Attachment. New York: Basic Books.

Darley, J. M., \& Fazio, R. H. (1980). Expectancy confirmation processes arising in the social interaction sequence. American Psychologist, 35, 867-881.

Deci, E. L., \& Ryan, R. M. (2000). The "what" and "why" of goal pursuits: Human needs and the self-determination of behavior. Journal of Health and Social Behavior, 2, 237-256.

Drigotas, S. M., Rusbult, C. E., Wieselquist, J., \& Whitton, S. (1999). Close partner as sculptor of the ideal self: Behavioral affirmation and the Michelangelo phenomenon. Journal of Personality and Social Psychology, 77, 293-323.

Emmons, R. A. (2003). Personal goals, life meaning, and virtue: Wellsprings of a positive life. In C. L. Keyes \& J. Haidt (Eds.), Flourishing: Positive psychology and the life welllived (pp. 105-128). Washington: APA.

Erikson, E. (1950). Childhood and society (2nd Ed.; pp. 247-269). New York: W. W. Norton. Freud, S. (1923). The ego and the id. New York: Norton.

Gombrich, E. H. (1995). The story of art (16th Ed.). London: Phaidon.

Gotlib, I. H., \& Whiffen, V. E. (1991). The interpersonal context of depression: Implications for theory and research. In W. H. Jones \& D. Perlman (Eds.), Advances in personal relationships (Vol. 3, pp. 177-206). London: Kingsley.

Harris, M. J., \& Rosenthal, R. (1985). Mediation of interpersonal expectancy effects: 31 meta-analyses. Psychological Bulletin, 97, 363-386.

Higgins, E. T. (1987). Self-discrepancy: A theory relating self and affect. Psychological Review, 94, 319-340.

Higgins, E. T. (1996). The "self digest": Self-knowledge serving self-regulatory functions. Journal of Personality and Social Psychology, 71, 1062-1083.

Ickes, W., Stinson, L., Bissonnette, V., \& Garcia, S. (1990). Naturalistic social cognition: Empathic accuracy in mixed-sex dyads. Journal of Personality and Social Psychology, 59, $730-742$.

Kelley, H. H., \& Thibaut, J. W. (1978). Interpersonal relations: A theory of interdependence. New York: Wiley.

Kumashiro, M., Rusbult, C. E., \& Estrada, M. J. (2004a). The Michelangelo phenomenon in everyday life: An interaction record study of self and partner processes. Unpublished manuscript, University of North Carolina, Chapel Hill, NC.

Kumashiro, M., Wolf, S., Coolsen, M., \& Rusbult, C. E. (2004b). Partner affirmation, verification, and enhancement as determinants of attraction to potential dates: Experimental evidence of the unique effect of affirmation. Unpublished manuscript, University of North Carolina, Chapel Hill, NC.

Markus, H., \& Nurius, P. (1986). Possible selves. American Psychologist, 41, 954-969.

Maslow, A. H. (1962). Toward a psychology of being. Princeton, NJ: Van Nostrand.

Moretti, M. M., \& Higgins, E. T. (1990). Relating self-discrepancy to self-esteem: The contribution of discrepancy beyond actual-self ratings. Journal of Experimental Social Psychology, 26, 108-123.

Murray, S. L., Holmes, J. G., \& Griffin, D. W. (1996). The self-fulfilling nature of positive illusions in romantic relationships: Love is not blind, but prescient. Journal of Personality and Social Psychology, 71, 1155-1180. 
Rogers, C. R. (1961). On becoming a person. Boston: Houghton Mifflin.

Rusbult, C. E., Coolsen, M., Kirchner, J., Stocker, S., Kumashiro, M., Wolf, S., Estrada, M. J., \& Clarke, J. (2004a). Partner affirmation and self movement toward ideal in newly-committed relationships. Unpublished manuscript, University of North Carolina, Chapel Hill, NC.

Rusbult, C. E., Kumashiro, M., Finkel, E., Kirchner, J., Coolsen, M., Stocker, S., \& Clarke, J. (2004b). A longitudinal study of the Michelangelo phenomenon in marital relationships. Unpublished manuscript, University of North Carolina, Chapel Hill, NC.

Rusbult, C. E., \& Van Lange, P. A. M. (2003). Interdependence, interaction, and relationships. Annual Review of Psychology, 54, 351-375.

Snyder, M., Tanke, E., \& Berscheid, E. (1977). Social perception and interpersonal behavior: On the self-fulfilling nature of social stereotypes. Journal of Personality and Social Psychology, 35, 656-666.

Swann, W. B., Jr., DeLaRonde, C., \& Hixon, J. G. (1994). Authenticity and positivity strivings in marriage and courtship. Journal of Personality and Social Psychology, 66, 857-869.

\section{Authors' addresses}

Caryl Rusbult

Department of Social Psychology

Free University at Amsterdam

Van der Boechorststraat 1

1081 BT Amsterdam

The Netherlands

E-mail: ce.rusbult@psy.vu.nl

Madoka Kumashiro

Department of Social Psychology

Free University at Amsterdam

Shevaun L. Stocker

Department of Psychology

University of North Carolina at Chapel Hill

Jeffrey L. Kirchner

Department of Psychology

University of North Carolina at Chapel Hill

Eli J. Finkel

Department of Psychology

Northwestern University

Michael K. Coolsen

John L. Grove College of Business

Shippensburg University 


\section{About the authors}

Caryl Rusbult is Professor and Chair in the Department of Social Psychology, Free University at Amsterdam. She completed her B.A. work at UCLA in 1974, and in 1978 she completed her Ph.D. work at the University of North Carolina at Chapel Hill. She has been the recipient of numerous honors, awards, and grants, for both research and teaching. Her work concerns behavior in close relationships, including commitment processes, relationship maintenance mechanisms (e.g., accommodation, forgiveness, derogation of alternatives), and self-processes in ongoing relationships.

Madoka Kumashiro is presently pursuing postdoctoral studies with Prof. Caryl Rusbult at the Free University at Amsterdam. She received her B.A./B.S from Lafayette College in 1994 and her Ph.D. from the University of North Carolina at Chapel Hill in 2004. Her primary research interests concern close relationships and the self - how self processes influence behavior in relationships, and how partners and relationships influence the self.

Shevaun Stocker is an advanced graduate student at the University of North Carolina at Chapel Hill, and presently is completing work on her Ph.D. doctoral dissertation. She received her B.A. degree from the University of Florida in 1996, and received her M.A. degree from the University of North Carolina at Chapel Hill in 2004. Her research concerns social-cognitive processes in interpersonal domains, including work on both counterfactual thinking and positive illusion.

Jeffrey Kirchner is presently completing his Ph.D. studies at the University of North Carolina at Chapel Hill. He received his B.A. degree from the Towson University in 1999, and in 2002 he received his M.A. degree from the University of North Carolina at Chapel Hill. His primary research interests concern interdependence processes, which he examines at both the dyadic and group levels, and in both close and non-close interpersonal settings.

Eli Finkel is an assistant professor in the Psychology Department at Northwestern University. He received his B.A. from Northwestern University in 1997 and his Ph.D. from the University of North Carolina at Chapel Hill in 2001. He served as a NIH National Research Service Award postdoctoral fellow at Carnegie Mellon from 2001 to 2003. His research resides at the intersection of close relationships and the self, including topics such as forgiveness, selfregulation, relational violence, interpersonal emotion regulation, and physical health.

Michael Coolsen is an assistant professor in the Marketing Department of the John L. Grove College of Business at Shippensburg University. He received his B.A. in 1992 from Lafayette College, and received his Ph.D. in 2003 from the University of North Carolina at Chapel Hill. His research interests include theory regarding close romantic relationships and the application of such theory to consumer behavior. 
Copyright of Interaction Studies is the property of John Benjamins Publishing Co.. The copyright in an individual article may be maintained by the author in certain cases. Content may not be copied or emailed to multiple sites or posted to a listserv without the copyright holder's express written permission. However, users may print, download, or email articles for individual use. 